\title{
Tras los vestigios ontológicos en el relato mítico del Yurupary: una aproximación fenomenológica
}

\author{
After the ontological remains in the mythical story \\ of Yurupary: a phenomenological approach
}

Após os restos ontológicos na narração mítica
do Yurupary: uma aproximação fenomenológica

Fecha de entrega: 15 de diciembre de 2013

Fecha de evaluación: 15 de abril de 2014

Fecha de aprobación: 13 de junio de 2014

Catalina González Sierra*

\section{Resumen}

En el presente texto se hace una lectura fenomenológica del relato mítico amazónico del Yurupary. A partir de esta, se defiende la tesis de que en la oralitura que se manifiesta en este relato se ofrece la cosmovisión de una cultura precolombina; en esta, se plasma en su estructura interna una determinada manera de estar-en-el-mundo, es decir, devela rasgos de la dimensión ontológica de la misma. Para exponer la tesis anterior el texto se divide en tres partes: I. "De la fenomenología o presupuestos metodológicos"; II. "Aproximación fenomenológica al relato", y III. "Perspectivas".

Palabras clave: fenomenología,Yurupary, ontología.

Filósofa de la Universidad de Cartagena con tesis Meritoria de pregrado evaluada por el Profesor. Dr.Mauricio Beuchot Puente UNAM. Docente y auxiliar de Investigacion en la Funación de Educación Superior Nueva América, Bogota, D.C.Hace parte de la Corporación en Investigación Cultural Comunicando Saberes de Cartagena. Correo electrónico: cata00005@hotmail.com 


\section{Abstract}

In the present text is subjected to phenomenological reading Yurupary Amazonian mythic narrative in the context of the following thesis: In the oraliteratura sedimented in the story materializes Yurupary mythical worldview of one of our pre-Columbian cultures and it is reflected in its structure inside a certain way of being-in-the-world, ie traits reveals the ontological dimension of it. Desglosaremos previous thesis from the following headings: I. The Fenomenologizar. I. Phenomenological Approach to the Story. Three. Perspectives.

Keywords: Phenomenology, Yurupary, Ontology.

\section{Resumo}

No presente texto se fez uma leitura fenomenológica da narração mítica amazonica do Yurupary. A partir dela, defende-se a tese de que na oralitura que se manifesta nesta narração oferece-se a cosmovisão de uma cultura pré-colombina; nesta, se plasma em sua estrutura interna uma determinada maneira de-estar-no-mundo, ou seja, revela traços da dimensão ontológica da mesma. Para expor a tese anterior o texto divide-se em três partes: I. "Da fenomenologia ou pressupostos metodológicos"; II. "Aproximação fenomenológica ao relato", e III. "Perspectivas".

Palavras-chave: fenomenologia, Yurupary, ontologia. 
El mito tiene sentido y verdad para la filosofía porque esta ha aceptado que, además del conocimiento condicionado, está el pensamiento de lo incondicionado [...]

PAul Ricceur

\section{De la fenomenología o presupuestos metodológicos}

Si revisamos las obras de Edmund Husserl, encontramos que reitera la naturaleza metodológica de la fenomenología e insististe en que la fenomenología es fundamentalmente un método que racionaliza la experiencia (Herrera, 2009). En este horizonte, la presente lectura fenomenológica del mito del Yurupary no se inscribe en una teorización particular de las diferentes fenomenologías existentes en nuestro días, sino que a partir de la perspectiva clásica husserliana se valdrá de la fenomenología estática desde una determinada intencionalidad protooperante. En suma, desde esta óptica, lo que nos interesa es aplicar el método y no teorizar acerca de este.

Desde esta perspectiva tenemos que la objetividad de las estructuras formales (como, por ejemplo, el símbolo, el mito, etc.) no dependen del sujeto. Sin embargo, el acto de dar sentido sí depende de este, y es en esto que consistirá el fenomenologizar. Al respecto Germán Vargas Guillen acota que:

La fenomenología es — desde sus comienzos - un retorno a la subjetividad como fuente de constitución del sentido. Que este recaiga sobre lo lógico, lo fáctico, lo cultural, lo subjetivo mismo es, sin más, campo de referencia, pero no altera el hecho de que es la subjetividad la que en todos los casos despliega el sentido de lo dado. (Vargas, 2012a, p. 7)

Obsérvese que la investigación en fenomenológica se realiza a partir del punto de vista del sujeto, quien, según Vargas:

[...] describiendo sus experiencias, el sentido que da a ellas en el mundo de la vida; y, simultáneamente, cuando más detallada es la descripción subjetiva de la experiencia de mundo y de sentido: más logra captar estructuras universales que valen para uno y valen para todos. (Vargas,2012a, pp. 8-9) 
Es en esto en lo que consiste su carácter epistemológico y científico. Este fenomenologizar siempre se da en una perspectiva en primera persona, y este es el horizonte (al respecto recuérdese que para Husserl existen tres clases de horizontes: externo, interno y horizonte de horizontes) desde el cual se tematiza el fenómeno que se estudiará. Esta tematización puede ser comprendida y compartida por otros en virtud de que está presente intersubjetivamente.

Es por eso que lo que se 've' desde la perspectiva de primera persona es comprensible para otros, y, de igual manera, la perspectiva de otro puede hacerse visible para mí. De esta manera, tenemos que el horizonte en el que se da la experiencia de los sujetos es, fenomenológicamente hablando, eminentemente intersubjetivo. En esta óptica, al volcar nuestra atención hacia estos fragmentos del mundo de la vida se puede fenomenologizar, esto es, hacer explícito el sentido que aflora de la experiencia subjetiva del fragmento del mundo objeto de la tematización. Así, en la presente investigación, “[...] nuestra 'mirada' se desplaza hacia la constitución de las objetividades culturales" (Vargas, p. 9), en este caso, en las del mito de Yurupary. Así, en concreto, se busca explicitar rasgos ontológicos presentes en el lenguaje metafórico del relato en los que se ubica la experiencia de mundo de sus actores.

\section{Aproximación fenomenológica al relato mítico del Yurupary}

El mundo que se nos presenta en del relato mítico del Yurupary es un microuniverso lleno de matices y símbolos, susceptible de que se le hagan lecturas e interpretaciones dignas de ser explicitadas. Dado su género literario, en el mito de Yurupary encontramos:

[...] un conjunto de símbolos colocados en forma de relato y como tal habla de Dioses y sus hechos en el tiempo originario y a partir de esa acción divina instaura la sociedad y la religión en el tiempo presente dentro de la cosmovisión de determinada cultura. (Fuster, 2011, p. 3)

En Yurupary, se presenta el contexto de la mitología de la zona de los indígenas del Vaupés, Guaviare y parte del Guainía. Por otra parte, entre los diversos tipos de mito, el Yurupary se clasifica dentro de los mitos del héroe, puesto que el héroe Yurupary 
realiza una gran lucha para lograr imponer las leyes de Sol. Este es uno de los rasgos por los que este mito es presentado académicamente como la gran epopeya del Vaupés y es caracterizado como poema heroico.

Asumiendo una lectura fenomenológica del relato se pueden traer a la luz algunos núcleos fenomenológicos ontológicos implícitos. Por consiguiente, dirigiremos la mirada hacia los símbolos presentes en el lenguaje metafórico del relato, $y$, mediante la selección de algunos fragmentos, explicitaremos la dimensión ontológica de los mismos.

Entonces, para dar nuestros primeros pasos en esta senda, nos preguntamos: ¿cuáles son los rasgos ontológicos implícitos en el lenguaje simbólico del relato mítico del Yurupary? En esta línea, adoptando una actitud reflexiva frente al relato, nos preguntamos de qué manera se despliega la operación dadora de sentido en el mundo del Yurupary.

En esta perspectiva, recordemos con Husserl que en la correlación entre noésis y noéma explicitar la intencionalidad de un fenómeno "[...] implica que para cualquier pensamiento - noesis - hay como polo correlativo algo pensado - noema- [...]. La correlación designa el hecho de que hay una reciprocidad entre pensar y lo pensado, el amar y lo amado, la espera y lo esperado, etc.” (citado, Vargas, 2012, p. 15).

A partir de esta consideración, si dirigimos la mirada al relato, encontramos que el Yurupary, como se mencionó anteriormente, está conformado por un conjunto de símbolos; de estos, centraremos nuestra atención en las analogías de tipo metafórico. Así, trataremos de explicitar la operación dadora de sentido que se presenta en las metáforas del texto, en cuanto constituyen una mediación lingüístico-cognitiva; en esta se presenta la experiencia de ser de esta comunidad. Recordemos que en el mito, al igual que en el sueño, el lenguaje aparece de manera cifrada, al decir de Paul Ricœur:

En principio y con mucha frecuencia, está distorsionado: quiere decir otra cosa de lo que dice, tiene doble sentido, es equívoco. El sueño y sus análogos se inscriben así en una región del lenguaje que se anuncia como lugar de significaciones complejas donde otro sentido se da y se oculta a la vez en un sentido inmediato; llamemos símbolo a esa región del doble sentido. (Ricœur, 1990, p. 10) 
En este horizonte, podemos decir entonces que lo que nos interesa es develar el sentido oculto, escondido en la primera cara que se nos muestra a través de los símbolos. Desde esta perspectiva, recordemos que, para Husserl, al mundo lo experimentamos lingüísticamente interpretado (Herrera, 2002). Al decir de Daniel Herrera: “[...] el presente viviente individual o colectivo, solo es experimentable porque en el lenguaje se ha sedimentado la experiencia pasada, la cual constituye un factor determinante de la existencia de horizonte que posibilita toda experiencia" (Herrera, 2002, p. 68). Por consiguiente, al adentrarnos en el relato mítico del Yurupary encontramos múltiples fragmentos contienen analogías de naturaleza metafórica en las que está "sedimentada la experiencia-vivencia de lo ontológico". Esta se puede clasificar en las siguientes categorías: elementos existenciales (cosmológico/antropológicos); símbolos y signos rituales; elementos eróticos, y tensiones. A continuación explicitaremos los aspectos ontológicos y los sentidos "sedimentados" en la pléyade de metáforas y analogías extrapolados del texto en cuestión.

\section{Elementos existenciales (cosmológico/antropológicos)}

El texto ofrece una explicación sobre el origen del mundo:

En el principio del mundo una terrible epidemia se desató entre los habitantes de la Sierra de Tenui, atacando exclusivamente a los hombres, solo se salvaron algunos viejos cansados y ya vencidos por los años, y un anciano payé. (Orjuela, 1993, p. 83)

Obsérvenos que como todo mito fundacional, el Yurupary narra el origen de una comunidad a partir de la extinción de otra raza a causa del mal. Sin embargo, la epidemia que allí se expone no ataca a un paye (léase chamán), es decir, respeta al puente e interlocutor entre el hombre y la divinidad.

Esto muestra cómo la intencionalidad significativa de la subjetividad protooperante en el texto devela un horizonte de sentido en el que lo mágico determina la manera de ser del presente. Además, desde una perspectiva fenomenológica del lenguaje como un organismo viviente, al decir de Herrera, “[...] no se reduce al mero correlato y significado de unos hechos, sino que posee una unidad de sentido que viene dada por el sujeto mismo constituyente de aquel sentido" (Herrera, 2002, p. 71). 
De manera análoga, en la huella de la voz que el Yurupary contiene está implicado un sentido (mágico del devenir de la existencia) y una determinada cosmovisión (mítica). En esta se interroga, en la noche de los tiempos, por las paradojas de la manifestación de toda existencia. Se plantea que la existencia se concretiza en diversos modos de ser, que afloran casi siempre en una tensión entre lo que se es y lo que se llegará a ser. Estos elementos se hacen patentes en las siguientes citas, en la que se articulan elementos del origen del mundo, cuya etiología alude a la acción de lo mágico en la espacio-temporalidad de lo cotidiano:

En el principio del mundo el señor de todas las cosas apareció sobre la tierra y dejó allí un pueblo tan feliz, que pasaba la vida solo bailando, comiendo y durmiendo. (Orjuela,1993, p.122)

Cuando Dinari completó diez lunas, dio a luz un varón y una niña. Y la niña tenía un puñado de estrellas en la frente, y el varón una serpiente, con las mismas estrellas, de la frente a los pies. Los dos niños nada tenían de la raza del padre; se parecían a la madre, llevando además las estrellas con las que habían venido al mundo. (Orjuela, 1993, p.127)

Ellos dormían y las estrellas que tenían sobre el cuerpo brillaban como las estrellas del cielo. (Orjuela, 1993, p.128)

Tú no nos has dado todavía un nombre, pero yo ya he elegido: me llamo Pinon (serpiente) y mi hermana Meenspuin (Fuego de estrellas). (Orjuela, 1993, p.137)

\section{Símbolos y signos rituales}

Los signos y los símbolos son sedimentaciones de sentido y percepciones categoriales de la subjetividad protooperante. Por esto, generan, como vestigios de experiencias fundantes, manifestaciones del ser de una determinada comunidad. En los signos y símbolos, lo sagrado, que da inicio a un nuevo tiempo o un nuevo acontecimiento, inaugura una nueva forma de ser-en-el- mundo y se hace presente a la consciencia bajo la plasticidad narrativa del lenguaje simbológico.

Esto se muestra en el Yurupary cuando se presenta la instauración del régimen patriarcal en el contexto simbólico de la "coronación" que otorga poderes de naturaleza divina al nuevo legislador. Además el poder divino, otorgado por las divinidades (Sol 
y Renstarlo), le permite al nuevo héroe culminar la gesta de la creación, a través de la fuerza significativa de los símbolos y de los signos que singularizan a este nuevo héroe. Al respecto el relato nos dice:

\begin{abstract}
A la víspera de su regreso, Yurupary había recibido de manos del Sol un matiry [bolsa] en el que estaban contenidos todos los poderes que le serían necesarios para llevar a cabo la reforma de las costumbres [...] Esa misma noche sacó Yurupary de su matiry una pequeña ollita y un pedazo de xicantá [resina] que puso sobre el fuego dentro de aquella. Con el primer hervor salió una cantidad de murciélagos, lechuzas y otros pájaros semejantes que se dispersaron en el espacio. Del segundo hervor nacieron guacamayas, papagayos, periquitos y otros pájaros por el estilo, que también se dispersaron en el aire. Del tercer hervor surgió una cantidad de pequeños gavilanes, y por último el uirá-uassú [águila], por medio del cual Yurupary se transportó a la Sierra del Gancho de la Luna. Rápidos como una flecha llegaron a la montaña donde estaba sentada la bella Renstarlo, que tenía en la mano del corazón los ornamentos de plumas y en la otra la itá-tuixáua [piedra del jefe]. Renstarlo misma invistió a Yurupary con los ornamentos de jefe sin proferir una sola palabra. (Orjuela, 1993, pp. 92-94)
\end{abstract}

Continuando con nuestra explicitación del sentido y de las materializaciones de la dimensión ontológica del texto, encontramos que, como en casi todos los relatos de naturaleza mítica, la sacralización del tiempo es un elemento esencial en el devenir óntico-existencial desde donde el sentido crea una comunión en torno a aquellas prácticas que están permitidas en un determinado tiempo bajo unas determinadas circunstancias y desde una determinada ritualidad que se debe acatar.

En esta línea, la celebración del tiempo festivo en el Yurupary se presenta desde unas determinadas situaciones de naturaleza simbólico-sacral-eróticas en las que los símbolos naturales son los vestigios del nuevo tiempo. En este sentido el relato nos dice:

Las fiestas tendrán lugar: cuando la chunaquyra [virgen] fuera desflorada por la luna [cuando la virgen tuviera su primera menstruación]. Cuando debiera comer la fruta de pihycan. Cuando debiera comer caza del monte. Cuando debiera comer carne de pescado grande. Cuando debiera comer pájaros. Pero todo esto después de que la chunaquyra hubiera pasado una luna entera, esperando su hora, y alimentándose con cangrejos, sauba [hormigas 
comestibles] y bejú [comida hecha de tapioca], sin verse ni tener contacto con hombre alguno. Cuando se celebra el dabacury [fiesta entre las tribus en épocas de solsticios en signo de amistad o paz] de fruta, pescado, caza u otro en prenda de buena amistad. Cuando se terminara un trabajo fatigoso como derribar árboles, construir casas, plantar roço, u otra labor semejante. Todos los ejecutantes de Yurupary llevarían en la mano una capeía [vara flagelante] para castigarse recíprocamente en recuerdo del secreto que deberían guardar. Todos aquellos que recibieran un instrumento de Yurupary lo que sucedería durante la siguiente luna llena, estarían obligados a ir a enseñar por todas las tierras del Sol, no solo las cosas ya dichas, sino también las que serían enseñadas en la fecha inaugural. (Orjuela, 1993, pp. 95-96)

\title{
Tensiones
}

El darse o la donación de la existencia se caracteriza por la tensión o dialéctica entre diferentes fuerzas, entre diversas perspectivas. En el relato del Yurupary, la tensión entre lo masculino y lo femenino como formas de estar-en-el-mundo y como locus epistémico de la constitución de sentido se evidencia en el tránsito de una comunidad matriarcal a una patriarcal. En este ámbito el texto nos dice:

\begin{abstract}
Arauyry, joven astuta y llena de maldad, dijo: -El que los hombres nos hayan abandonado sin motivo y sin decirnos nada, quiere decir que nunca volverán a poner los pies aquí; por eso, y para que no se propague la raza de estos hombres sin amor, sin corazón, propongo que se les de muerte a todos los niños varones. (Orjuela, 1993, p. 171)
\end{abstract}

Al volver la mirada a la cita anterior se observa que la tensión entre el poder matriarcal y el patriarcal genera sentimientos de odio hacia los hombres, en la medida en que representan un modo de exitir diferente al femenino y se sublevan al dominio femenino. Por su parte, la tensión de lo masculino hacia lo femenino y la transición al patriarcado se expone en el mito dentro de un marco ritual en el que el poder del héroe Yurupary se funda en la voluntad divina. Al respecto el mito expone: "[e]n la víspera de su regreso, Yurupary había recibido de manos del Sol un matiry [bolsa] en el que estaban contenidos todos los poderes que le serían necesarios para llevar a cabo la reforma de las costumbres" (Orjuela, 1993, p. 92). 
Véase cómo en la simbología del mito los poderes son donados por una entidad divina que otorga autoridad al héroe. Empero, el punto álgido de la tensión entre la subjetividad femenina y la masculina aparece en el mito del Yurupary en la simbolización de naturaleza cosmológica en la que el Sol busca una mujer perfecta. Observemos que la 'perfección' que busca el Sol hace alusión a elementos éticos tales como la prudencia. Al no encontrarla, la intencionalidad donadora de sentido que permea el mito justifica desde la perspectiva cosmológico-sacral el tránsito al patriarcado. El mito nos expone esta justificación de la siguiente manera:

\begin{abstract}
El Sol, desde que nació la tierra, ha buscado una mujer perfecta para llevarla cerca de él, pero como aun no la ha encontrado, me dio parte de su poder para que viera si en el mundo puede encontrarse una mujer perfecta. ¿Y cuál es la perfección que el Sol desea? Que sea paciente, que sepa guardar un secreto y que no sea curiosa. Ninguna mujer existente hoy en la tierra reúne esas cualidades: si una es paciente, no sabe guardar un secreto; si sabe guardar un secreto, no es paciente, $y$ todas son curiosas; quieren saberlo y experimentarlo todo. $Y$ hasta ahora no ha aparecido la mujer que el Sol quiere tener. (Orjuela, 1993, p. 211)
\end{abstract}

\title{
Elemento erótico
}

A pesar de las prohibiciones que pululan en diferentes pasajes del mito, no deja de sorprender que el pasaje que relata la concepción de Yurupary se caracterice por su explicita alusión al origen divino y misterioso del héroe, dado que el símbolo de la fruta del árbol del pihycan nos remite a otros mitos en los que hay una prohibición hacia una fruta, por ejemplo el relato bíblico el génesis.

Otra de las particularidades del pasaje que nos ocupa aparece en el propósito explícito del texto es subrayar el origen sagrado del Yurupary, pues su existencia es un acto sui generis, en el que lo divino, representado por el símbolo de la fruta, genera una existencia singular. Esta, a pesar de provenir de una transgresión a las prohibiciones ancestrales, genera una ruptura singular en el ethos de la comunidad en virtud de la irrupción de lo sagrado en el ámbito profano. Esta irrupción produce una asimetría ontológica. En esta, lo totalmente otro se relaciona con lo finito y reordena la existencia general de una comunidad. En el mito este acontecimiento se nos revela en una urdimbre de símbolos: 
Entre los recién nacidos había una espléndida niña, que por su belleza fue llamada Seucy. La Seucy de la tierra era la réplica de la Seucy del cielo y creció hasta la edad de los primeros amores tan pura como la estrella de la mañana. Un día quiso comer de la fruta de pihycan y se internó en la selva. Fácilmente encontró la fruta apetitosa y no le fue difícil alcanzarla [...] La bella muchacha eligió las más hermosas y maduras, y habiéndolas amontonado frente a ella, comenzó a comerlas. Eran tan suculentas, que parte del jugo se le escurrió por entre los pechos, mojándole las partes más ocultas, sin que ella diera a esto menor importancia. Comió hasta saciarse y no regresó a su casa hasta la hora de las tristezas, contenta de haber satisfecho un deseo nutrido por mucho tiempo. Pero sentía los miembros estropeados por una extraña sensación jamás experimentada hasta entonces. Movida por un instinto natural, se examinó atentamente y se dio cuenta que su virginidad ya no existía y que en sus vísceras había algo desconocido [...] Después de diez lunas dio a luz un robusto niño que superaba en belleza a su madre; se parecía al Sol. (Orjuela, 1993, pp. 87-88)

Para terminar, se puede advertir que en el Yurupary lo erótico se articula con las prohibiciones o tabú. Por ejemplo, la virginidad y la concepción de origen divino determinan el destino de sus protagonistas principales. Estos alcanzan una simbiosis con lo divino en virtud del cumplimiento de dichas prohibiciones. He aquí como la subjetividad donadora de sentido en el texto nos remite a la constante búsqueda de la religación entre lo humano y lo sacral. El mito nos dice al respecto:

Meenspuin, llegada a la pubertad, comenzó a sentir deseos que no comprendía, y estaba por eso tan incómoda que le dijo a su madre:/—Mamá, sufro un mal que al manifestarse me da un deseo que no sé explicar.-¿Qué es lo que sientes?-Cuando mi mal comienza es una picazón, un malestar que me da y que no produce dolor, y este dolor que no duele me recorre después por todo el cuerpo con voluntad de morderme toda, hasta que al fin me siento desfallecer y lloro. Cuando duermo veo siempre cerca de mi hamaca a unos jóvenes hermosos que unas veces quieren besarme, otras abrazarme, y yo no puedo huir. [...] Para asegurar la virginidad de su hermana, Pinon la condujo a la Sierra de las Piedras Blancas, y para alcanzar las puertas del cielo abrió un pasaje por el cual subieron hasta el país de las estrellas; allí dejó a Meenspuin, a quien otros llaman Seucy. (Orjuela, 1993, pp. 140-142). 


\section{Perspectivas}

Con la aproximación fenomenológica que hemos realizado anteriormente, podemos ver de qué manera afloran algunos rasgos ontológicos en la simbología implícita en el relato del Yurupary. Así, observamos que la operación dadora de sentido se despliega a partir de la vivencia-experiencia de lo ontológico, dentro de algunos fragmentos del corpus del mito. Estos rasgos ontológicos se hicieron explícitos a partir de la clasificación de distintos elementos en el relato, como los existenciales (cosmológico/ antropológicos), símbolos y signos rituales, elementos eróticos y tensiones.

En estos elementos encontramos inmerso un sentido mágico del devenir de la existencia y una determinada cosmovisión mítica. En esta última aflora en su estructura interna una determinada manera de estar-en-el-mundo propia de nuestros ancestros precolombinos de la zona del Vaupés. En esta, la irrenunciable tarea de afrontar el ser fue encarada a partir de un pensamiento a través de imágenes que aún entabla diálogo con el pensar conceptual del filosofar. 


\section{Referencias}

Chicano, J. (2006). El lenguaje religioso cristiano desde la perspectiva simbólica. Naturaleza y Gracia, (1), 7.108.

Fuster, S. (2011). Mito y rito en la cosmovisión bíblica: Aplicaciones metodológicas desde la fenomenología de la religión. Ponencia presentada durante el Congreso de Estudios del Antiguo Cercano Oriente. Buenos Aires.

Herrera, D. (2002) La persona y el mundo de su experiencia: contribuciones para una ética fenomenológica. Bogotá: Universidad de San Buenaventura.

Herrera, D. (2009). Por los senderos del filosofar (C. Jaramillo y M. Villamil, Eds.). Bogotá: Bonaventuriana.

Husserl, E. (1962) Ideas relativas a una fenomenología pura y una filosofía fenomenológica (José Gaos, Trad.). México: Fondo de cultura económico.

Husserl, E. (1982). Investigaciones lógicas (Manuel G. Morente y José Gaos, Trads.). Madrid: Alianza.

Orjuela, H. H. (1993). Yurupary: mito, leyenda y epopeya del Vaupés (Vol. 64). Instituto Caro y Cuervo.

Reeder, H. (2011) La praxis fenomenológica de Husserl. Bogotá: San Pablo.

Ricœur, P. (1990). Freud: Una interpretación de la Cultura. México: Siglo veintiuno.

Vargas, G., y Reeder, H. (2009). Ser y sentido: Hacia una fenomenología trascendental- hermenéutica. Bogotá: San Pablo.

Vargas, G. (2012a). En torno a la fenomenología de la fenomenología: la pregunta por el método. Ponencia presentada en el IV Congreso Iberoamericano de Filosofía "Filosofía en Diálogo" y en el VI Coloquio Latinoamericano de Fenomenología. Santiago de Chile.

Vargas, G. (2012b) La fenomenología de los invisible: el problema del método. Revista de Filosofía ódóc, (2), 86-99. 